\title{
DIREITO AO LAZER E LEGISLAÇÃO VIGENTE NO BRASIL
}

\author{
Autora: Marcela Andresa Semeghini Pereira ${ }^{1}$
}

\section{RESUMO}

O objetivo desta pesquisa é discutir o direito ao lazer que, apesar de não ser juridicamente sistematizado na legislação, podemos encontrá-lo de forma pulverizada na Constituição Federal e na CLT (Consolidação das Leis do Trabalho). O estudo de tal tema tem sido essencialmente voltado à vertente social e psicológica da sua prática a discussão jurídica é praticamente inexistente. Com esta pesquisa pretende-se apresentar aspectos da legislação do trabalho, conceitos e teorias sobre o lazer e sua história que se desenvolveu junto à do Direito do Trabalho. A metodologia utilizada foi basicamente a doutrina que trata do Direito do Trabalho e consequentemente do Direito ao Lazer também as leis, tendo em vista que este direito se encontra disperso em todo ordenamento jurídico.

Palavras Chaves: direito ao lazer, trabalho, CLT, Constituição.

\section{LEISURE AND THE LAW IN BRAZIL LEGISLATION}

\begin{abstract}
The objective of this research is to discuss the right to leisure which, although not legally be systematized in the legislation, we can find it powdered form in the Federal Constitution and the CLT (Consolidation of Laws Labor). The study of this issue has been mainly ocused on social and psychological aspects of their practice is to discuss legal virtually nonexistent. With this research aims to provide aspects of employment law, concepts and theories about the leisure and its history which has developed close to the Labor Law. A methodology was essentially the doctrine of law that deals with Work and therefore also the Right to Leisure laws, taking into view that this right is dispersed throughout the legal system.
\end{abstract}

Keywords: entertainment, right, labor, security, law.

\footnotetext{
${ }^{1}$ Mestranda em Direito pelo Centro Universitário Eurípides de Marília - UNIVEM
} 


\section{1 - Introdução}

O direito do trabalho vem sendo debatido durante décadas através de artigos, revistas, livros, convenções, seminários etc. A importância e relevância deste direito deu-se juntamente com o processo de urbanização, industrialização (maquinismo, eletrificação, eletrônica ou automatização) e a comunicação de massa, elementos característicos da Revolução Industrial.

Com a sistematização do direito do trabalho, a restrição da jornada de trabalho, férias, abonos, folgas etc. surge também o direito ao lazer que possui funções essenciais para qualidade de vida e desenvolvimento social e psicológico do ser humano. O direito ao lazer não possui legislação específica e também não possui esta denominação.

O lazer é essencial para manutenção da saúde, integridade física e mental do trabalhador, considerando a importância do direito ao lazer tanto quanto do direito ao trabalho, este artigo apresenta, na primeira parte a história do trabalho, juntamente com o lazer e as primeiras leis trabalhistas; na segunda parte apresenta-se o conceito do termo lazer e seu surgimento, por fim a apresentação do lazer na legislação brasileira (CLT e Constituição Federal).

\section{2 - História do Direito do Trabalho e suas conquistas}

O intérprete e o legislador, conscientes de seus atos e deveres realizadores da justiça, precisam aprofundar sua visão processual, observando o que fizeram as gerações pretéritas e ampliar seus horizontes, para tanto iniciaremos este artigo com a origem do Direito do Trabalho e, junto com este, a necessidade de um Direito ao Lazer.

A categoria do trabalho existe desde o surgimento do homem, tendo em vista que este precisava trabalhar para obter o alimento, que era sua principal necessidade: esta é a primeira fase do homem sociológico. A palavra latina que dá origem ao vocábulo "trabalho" é tripalium, instrumento de tortura para empalar escravos rebeldes e derivada de palus, estaca, poste onde se empalam os condenados. Labor (em latim) significa esforço penoso, dobrar-se sob o peso de uma carga, dor, sofrimento, pena e fadiga.

Para Marx (1980) e Lafargue (2000), o trabalho é uma das dimensões da vida humana que revela nossa humanidade, é por ele que se dominam a força da natureza e é 
por ele que satisfazemos nossa capacidade inventiva e criadora - o trabalho exterioriza, numa obra, a interioridade do criador. Para estes autores a moral do trabalho é a moral de escravos e certamente o mundo moderno não precisa e não quer a escravidão.

A escravidão predominou como forma de trabalho, no período pré-industrial. $\mathrm{O}$ escravo nada mais era do que uma mercadoria, não tendo nenhum tipo de direito trabalhista. Conforme explicita Vianna (1999), escravidão era considerada justa e útil, Aristóteles (2001) afirmava que, para o homem adquirir cultura, era preciso ser rico e ocioso e isso somente seria possível com a utilização dos escravos. Para este pensador, na espécie humana existem seres tão inferiores a outros quanto o corpo o é em relação à alma, ou a besta ao homem; são aqueles para os quais a utilização da força física é o melhor que deles se consegue. Para ele, a escravidão é uma condição natural.

Quando servo, embora com alguma proteção oferecida pelo senhor feudal, não tinham liberdade alguma, trabalhavam apenas nas terras de seus senhores. Os servos tinham alguns direitos como o direito de herança de animais, objetos pessoais e até mesmo do uso de pastos, mas os herdeiros deveriam pagar impostos de herança que eram tão exorbitantes que se tornava inviável receber a herança.

Com o surgimento das Corporações de Ofício, na Idade Média, o trabalhador adquiriu liberdade parcial. O homem que apenas trabalhava para o outro passou a trabalhar para si mesmo passando a exercer atividade organizada de forma coletiva. Esta liberdade do trabalhador não era plena, pois surgiram os mestres que ordenava e chefiava os aprendizes e os trabalhadores. Em troca, os mestres ofereciam salário, assistência médica e asseguravam o monopólio da profissão. As corporações nada mais eram do que uma forma camuflada e branda de controle dos homens para atender apenas aos anseios dos mestres (VIANNA, 1999).

O aparecimento do Direito do Trabalho se deu apenas no século XVIII, com a Revolução Industrial, na Inglaterra. Com a invenção da máquina e sua utilização ocorreram mudanças nos métodos de trabalho e nas relações entre patrão e empregado. A máquina a vapor, o tear mecânico e a expansão do comércio e da indústria acarretaram em uma drástica redução da mão-de-obra utilizada e a conseqüente substituição do trabalho escravo, servil e corporativo pelo trabalho assalariado (VIANNA, 1999).

Antes da Revolução Industrial um homem era capaz de produzir, trabalhando arduamente, um pouco mais do que o necessário para sua própria manutenção e a de sua família, a mulher e os filhos também ajudavam. O que excedia as necessidades básicas 
não ficava para os produtores, pois era apropriado pelos guerreiros e sacerdotes. Após a Revolução, os trabalhadores eram forçados a produzir mais e entregar o excedente, desta forma eles trabalhavam para que outros pudessem praticar o ócio.

A Revolução e as técnicas modernas trouxeram a possibilidade de que o lazer, dentro de certos limites, fosse um direito de todos, distribuído por toda a coletividade. $\mathrm{O}$ lazer é essencial à civilização. A técnica moderna tornou possível a redução da quantidade de trabalho necessária para garantir a todos que tivessem satisfeitas todas as necessidades básicas.

Para os católicos, o trabalho é uma condenação, como consta na Rerum Novarum - teoria de maior difusão entre as massas católicas do final do século XIX e início do século XX (encíclica escrita pelo Papa Leão XIII em 1891, tendo em vista de que este temia tanto o conflito de classes quanto as teorias defendidas pelos socialistas e pelos liberais).

A Revolução Industrial na América enraíza-se tão rapidamente porque existe uma minoria, a dos patrões, que está convencida de que quem possui fortuna neste mundo a merece, pois esta é à vontade de Deus. As massas católicas embebidas da Rerum Novarum que tinham ouvido em todas as igrejas estavam convencidas de que tinham o dever de sofrer em silêncio e trabalhar.

Consta na encíclica que o homem deve aceitar com paciência a sua condição, pois é impossível que na sociedade civil todos sejam elevados ao mesmo nível, portanto as diversas classes devem entrar num acordo, em nome de um organicismo.

Com o intermédio dos sindicatos os trabalhadores reivindicavam um direito que os protegessem, desejavam uma legislação que iniba os abusos do empregador e preserve a dignidade humana.

O trabalho apresenta-se como um marco histórico e determinante da organização social, econômica, política e cultural. Observa-se que todas as transformações ocorridas no trabalho interferem diretamente em todas as esferas da organização social.

\subsection{As primeiras leis trabalhistas}

As primeiras leis trabalhistas foram ordinárias e posteriormente constitucionais. A primeira constituição do mundo que dispõe sobre Direito do Trabalho é a do México, em 1917, que em seu art. 123 disciplina a jornada diária de 8 (oito) horas, a jornada 
máxima noturna de 7 horas, limita a jornada do menor de 16 anos a 6 (seis) horas, o descanso semanal, a proteção à maternidade e outros direitos mais.

As leis trabalhistas, de cunho protecionista, preocuparam-se em limitar a jornada diária do trabalho, sendo necessário fixar um tempo razoável de trabalho humano prestado nas empresas da sociedade industrial.

A respeito da jornada de trabalho, foram elaboradas na Inglaterra (1847) e na França (1848), onde foi estabelecida a jornada de dez e onze horas, justificando que o trabalho manual muito prolongado arruinaria a saúde do trabalhador e o impediria de desenvolver sua inteligência, o que prejudicaria a sua dignidade. Outros países também adotaram medidas parecidas, dentre esses a Suíça (1877), fixando jornada em onze horas, a Áustria (1885), em dez horas, os Estados Unidos (1868), em oito horas no serviço federal, a Rússia (1887) em dez horas.

Acreditando que o trabalho não deve se prolongar por mais tempo do que as forças do homem permitem a jornada de oito horas foi se generalizando no início do século XX.

O Tratado de Versalhes, de 1919, efetivou a jornada diária de oito horas com a Organização Internacional do Trabalho e a promulgação da Convenção n. 1 pela Conferência de Washington.

As primeiras leis trabalhistas na Europa foram elaboradas para coibir os abusos sofridos pelo proletário e a exploração sofrida pelas mulheres e menores de idade. Surgiram leis limitando a idade para trabalho na indústria e duração diária do trabalho.

No período contemporâneo, ressaltando a diminuição do emprego no setor industrial, é dado um destaque maior às normas de respaldo ao sindicalismo, a proteção contra o desemprego e ampliação das negociações coletivas, mas este é um assunto um tanto complexo não nos cabendo discorrer a respeito.

Quanto às leis sociais brasileiras, foi após a Revolução de 1930, após a criação do Ministério do Trabalho, Indústria e Comércio, que iniciou-se a fase da legislação trabalhista.

Conforme Requixa (1977) é nas cidades, nas condições urbanas de civilização (indústria, comércio), que se apresentam, de forma mais perfeita e racional, a legislação trabalhista e as relações entre o capital e o trabalho.

\section{3 - Lazer: surgimento e conceito}


Requixa (1977) afirma que, com a urbanização e a industrialização, os meios de comunicação de massa se desenvolvem, surge a sociedade moderna e se fortalece o lazer de massa. Apesar dos esforços para a formação de uma espécie particular de cultura, a cultura operária não se sobressaiu no Brasil. Os meios de comunicação de massa, a industrialização e a urbanização padronizaram as condutas sociais no lazer como elemento cultural de uma sociedade de massa.

Lafargue (2000, p. 112) apresenta o Lazer como um momento para exercer a sua consciência, momento em que a classe proletária possui liberdade de pensamento e consciência de sua condição como ser explorado:

Se, extirpando do peito o vício que a domina e que avilta sua natureza, a classe operária se levantasse em sua força terrível, não para exigir os Direitos do Homem, que não passam dos direitos da exploração capitalista; não para reivindicar o Direito ao Trabalho, que não passa do direito à miséria, mas para forjar uma lei de bronze que proíba o trabalho além de três horas diárias, a terra, a velha Terra, tremendo de alegria, sentiria brotar dentro de si um novo universo... Mas como exigir de um proletário corrompido pela moral capitalista uma decisão tão viril? Como Cristo, dolente personificação da escravidão antiga, os homens, mulheres e crianças do proletariado sobem penosamente, há um século, o duro calvário da dor; há um século, o trabalho forçado quebra seus ossos, mata suas carnes, esmaga seus nervos; há um século, a fome retorce suas entranhas e alucina suas mentes!... Preguiça, tenha piedade de nossa longa miséria! Preguiça, mãe das artes e das virtudes nobres, seja o bálsamo das angústias humanas!

Lafargue propõe de forma fantástica a conscientização dos trabalhadores para que lutem a favor da redução do tempo trabalhado, no entanto, reconhece que estes homens estão corrompidos pela moral capitalista. Apela, então, para uma oração à Santa Preguiça, mãe de todas as virtudes, Santa Libertadora e Curadora das angústias humanas.

Apesar de existir formas de lazer em todas as sociedades, para alguns, o lazer aparece como um fenômeno intrinsecamente ligado à industrialização, pois, nesta fase, o capitalismo o expande a todos os campos da atividade humana fora da esfera de produção.

O significado da palavra lazer não é fácil de ser definido. Existem algumas dificuldades para conceituar este termo, pois além de existirem vários conceitos apontados, o lazer é apresentado como fenômeno essencialmente problemático e ambíguo.

No Brasil, há escassez de estudos sobre o lazer, diferentemente do que se apresenta nos Estados Unidos, União Soviética e muitos países da Europa Ocidental. 
Com o grande volume e a qualidade dos estudos feitos, já foi reivindicado o surgimento de uma Sociologia do Lazer.

Dentre as várias definições de lazer, a mais adotada pelos estudiosos é a dada por Dumazedier (1973, p. 34)

O lazer é um conjunto de ocupações às quais o indivíduo pode entregar-se de livre vontade, seja para repousar, seja para divertir-se, recrear-se e entreter-se ou, ainda, para desenvolver sua informação ou formação desinteressada, sua participação social voluntário ou sua livre capacidade criadora após livrar-se ou desembaraçar-se das obrigações profissionais, familiares e sociais.

Percebe-se que o autor relaciona o lazer com a satisfação de algumas necessidades humanas como o repouso, diversão, recreação, distração, desenvolvimento intelectual. Para ele o lazer é uma atividade, ou inatividade voluntária, onde o homem se sente liberto de qualquer grilhão.

O que se verifica com frequiência, é a simples associação do lazer com experiências individuais vivenciadas, o que reduz o lazer a conceitos de visões parciais, restritas aos conteúdos de determinadas atividades. O lazer, comumente, é relacionado ao divertimento e ao descanso.

Lazer não é sinônimo de não-fazer, pois inclui esforços físicos capazes de satisfazer o homem, podemos citar: praticar esportes, sair para dançar, escrever um livro dentre outros.

Nelson Carvalho Marcellino (1995, p. 31) entende o lazer como

(...) como a cultura - compreendida no seu sentido mais amplo - vivenciada (praticada ou fruída) no 'tempo disponível'. O importante, como traço definidor, é o caráter 'desinteressado' dessa vivência. Não se busca, pelo menos fundamentalmente, outra recompensa além da satisfação provocada pela situação. A 'disponibilidade de tempo' significa possibilidade de opção pela atividade prática ou contemplativa.

O autor dá muita ênfase à voluntariedade dá ação ou omissão realizada pelo homem, o lazer deve ter caráter voluntário e livre de obrigações ou coações externas o que se busca é a satisfação pessoal.

Conforme dispõe Marcellino (1995), há autores como Davi Riesman que consideram o lazer como uma atitude, um estilo de vida que não depende de tempo determinado, e há autores que privilegiam o aspecto do tempo como Dumazedier e Fourastié, sendo o lazer todo tempo livre de qualquer trabalho e obrigação, seja ela social, religiosa, política. Aos que consideram o lazer como atitude, o lazer é a satisfação provocada pela atividade, assim, até mesmo quando trabalhando pode-se 
sentir prazer. Os que restringem o lazer a um tempo estipulado acreditam que, num certo período de tempo, uma pessoa pode assistir desenho animado enquanto trabalha. Devendo ressaltar que em nenhum momento ele estará livre de coação e de normas de conduta.

A visão funcionalista do lazer é reacionária e conservadora, busca a paz social, a manutenção da ordem, o controle social. Esta se divide em: romântica, utilitarista e compensatória (MARCELINNO, 1995).

Segundo Marcelinno (1995), para os adeptos a visão romântica como Schmidt o lazer tem uma conotação extremamente positiva e feliz. Chegam a fazer poesia com a palavra lazer que é considerada plena de alegria, beleza e liberdade.

Para os adeptos da visão compensatória (REQUIXA, 1977), o lazer deve ser usado para restaurar a dignidade do homem, pois este foi reduzido a subproduto mecanizado que gasta suas energias em um trabalho inumano. O trabalho torna-se um meio de vida e não mais fonte de auto-realização ou finalidade de vida. A função do lazer seria compensar a insatisfação e a alienação sofrida pelo trabalhador.

A visão utilitarista reduz a função do lazer a de recuperar as forças e energias do trabalhador, ou sua utilização como instrumento de desenvolvimento.

Além de buscar o prazer, a diversão o lazer deve possibilitar ao trabalhador que ele pare para pensar, refletir, e isto possibilita que ele se encontre consigo próprio, com sua realidade social, com os conflitos e crises que o permeiam, o momento de lazer pode ser o único momento em que o trabalhador se sente apto a questionar sua realidade social, podendo ter como função principal a auto-conscientização do trabalhador.

O tempo de lazer deve ser considerado como um tempo privilegiado, que propicie mudanças de sociais, morais e políticas ${ }^{2}$. Por isso, podemos afirmar que na nossa sociedade o que ocorre é o antilazer, a negação do lazer, pois o tempo de lazer só serve para alimentar a alienação e manter as pessoas integradas ao modo de vida industrial, capitalista. O lazer deveria fazer com que pensemos em nossa realidade social, e não nos divertir ou possibilitar às pessoas que se integrem perfeitamente na sociedade industrial e urbana, servindo consequentemente, como instrumento de dominação.

\footnotetext{
${ }^{2}$ Podemos utilizar um exemplo típico de forma de lazer para manter a alienação e o controle da sociedade: a política do "pão e circo", que foi realizada no Império Romano (exemplo utilizado por Dumazedier no texto Lazer e Cultura Popular, 1973).
} 
O tema lazer despertou interesse nos estudiosos da medicina que o considera como fonte restauradora da higidez (saúde) da pessoa e de suas energias, fatos associados a mudanças de hábitos ou quebra de rotina existencial; e o considera como modus vivendi, modo de viver, de aproveitar a vida. Conforme dispõe Martinez (1997, p.286):

Para o trabalhador, massacrado pela rotina do dia-a-dia, o descanso e a alternância de ares, são absolutamente imprescindíveis ao seu restabelecimento periódico. Às vezes, o simples distanciamento do local de trabalho, mediante viagens, é suficiente para o reequilíbrio da força perdida.

O trabalhador necessita do momento de lazer não apenas para sua saúde física, mas principalmente para sua saúde mental. A mera mudança de local pode ajudar o homem a se sentir livre para pensar e agir, pois quando trabalha o homem fica subordinado ao que lhe é ordenado e estabelecido não havendo possibilidade de fuga.

\section{1 - As determinações legais do Direito ao Lazer}

O direito ao lazer não é juridicamente sistematizado na legislação. Ele não é nada além do que uma manifestação do pensamento humano, sem proteção legal, não lhe sendo atribuída nenhuma área específica. $O$ estudo de tal tema tem sido essencialmente voltado à vertente social e psicológica da sua prática, a discussão jurídica é praticamente inexistente.

Juridicamente, o lazer é uma faculdade natural do ser humano que deve ser amplamente reconhecida pelo direito positivo. Durante a infância, por inaptidão para o trabalho, o tempo deve ser naturalmente, reservado para brincadeiras, diversões e educação. Tem a função de restaurar as energias nos períodos de trabalho e, por fim, àquele que contribuiu para criar riquezas tem o direito de se aposentar.

Apesar de não sistematizado, encontramos algumas manifestações formais como forma de garantia e legitimidade do lazer na Magna Carta e na CLT (Consolidação das Leis do Trabalho).

Consta expressamente na Constituição Federal, em seu art. $6^{\circ}$ que:

São direitos sociais a educação, a saúde, o trabalho, a moradia, o lazer, a segurança, a previdência social, a proteção à maternidade e à infância, a assistência aos desamparados, na forma desta constituição (BRASIL, 1988). 
Observa-se que, o lazer apresenta-se como um direito social, todo ser humano, portanto, tem não apenas a possibilidade, mas o direito a ele. A importância do direito ao lazer, que é constantemente suprimida e desvalorizada, está relacionado junto com o direito à segurança (que está no ápice de sua discussão) e outros direitos também essenciais ao ser humano como a educação, saúde, moradia e o próprio trabalho.

Os direitos sociais, junto com os direitos individuais, coletivos, da nacionalidade e políticos/democráticos ou da cidadania são direitos fundamentais do homem, sendo o lazer também um direito fundamental. Para que entendamos os direitos sociais é necessário que apresentemos os direitos fundamentais. Segundo Canotilho (apud MORAES, 2000, p. 56) aos direitos fundamentais cumprem

(...) a função de direitos de defesa dos cidadãos sob uma dupla perspectiva: (1) constituem, num plano jurídico-objectivo, normas de competência negativa para os poderes públicos, proibindo fundamentalmente as ingerências destes na esfera jurídica individual; (2) implicam, num plano jurídico-subjectivo, o poder de exercer positivamente direitos fundamentais (liberdade positiva) e de exigir omissões dos poderes públicos, de forma a evitar agressões lesivas por parte dos mesmos (liberdade negativa).

Os direitos fundamentais primam em garantir uma vida digna, em que os princípios da igualdade, da liberdade e da fraternidade3 devem ser objetivados e respeitados, sem distinções entre os homens. Constitui garantia fundamental, pois sem este direito a pessoa não sobrevive, ou não possui vida social e a todo homem cabe o reconhecimento e a consolidação destes. Os direitos fundamentais são inerentes ao homem, são inalienáveis (intransferíveis, não se pode desfazer deles), são imprescritíveis (nunca deixam de ser exigíveis) e irrenunciáveis (não se renuncia).

Os direitos sociais, um dos tipos de direito fundamental, são apontados como liberdade positiva que deve ser vigiada de forma obrigatória em um Estado social de Direito e tem como finalidade a melhoria nas condições de vida dos mais fracos e mais carentes devendo ampará-los evitando a distinção social. tais direitos são essenciais, sendo de obrigação do Estado à preservação destes tendo como função e objetivo preservar e resgatar a igualdade social. A Constituição Federal dispõe sobre os direitos sociais em seus art. $6^{\circ}$ ao $11^{\circ}$, de forma exemplificativa, não os esgotando visto que se encontram espalhados de forma difusa, por toda Constituição Federal.

\footnotetext{
${ }^{3}$ Tais princípios foram ideais da Revolução Francesa de 1789, e passaram a ser constitucionais com a Declaração dos Direitos do Homem e do Cidadão.
} 
Silva (2001) define os direitos sociais como prestações positivas oferecidas pelo Estado de forma direta ou indireta, enunciadas em normas constitucionais, que propiciam melhores condições de vida aos hipossuficientes, tende a realizar a igualdade às situações desiguais.

Dessa forma, é obrigatório ao Estado proporcionar ao trabalhador o direito ao lazer, sendo este um direito fundamental, social que é imprescindível, irrenunciável, indelegável. O direito ao lazer proporciona ao homem fazer uso de sua liberdade, de sua criatividade e relacionar-se com o outro. O lazer é o momento de prazer e ser do homem e por isto tem grande importância.

O descanso do trabalhador, que é uma das possibilidades de lazer, junto com o direito de férias e do gozo dessas férias da forma que o empregado desejar, como: viajar, estudar, ler, dormir, passear etc., são direitos sociais do trabalhador.

A Constituição Federal assegura o direito ao descanso, o direito ao repouso, às férias e ao gozo destas, a aposentadoria no art. $7^{\text {a }}$, incisos XIII, XIV, XV, XVI, XVII, XVIII, XIX E XXIV, que são respectivamente:

Art. XIII - duração do trabalho normal não superior a oito horas diárias e quarenta e quatro horas semanais, facultada a compensação de horários e a redução da jornada, mediante acordo ou convenção coletiva de trabalho;

Art. XIV - jornada de seis horas para o trabalho realizado em turnos ininterruptos de revezamento, salvo negociação coletiva;

Art. XV - repouso semanal remunerado, preferencialmente aos domingos;

Art. XVI - remuneração do serviço extraordinário superior, no mínimo, em cinqüenta por cento à do normal;

Art. XVII - gozo de férias anuais remuneradas com, pelo menor, um terço a mais do que o salário normal;

Art. XVIII - licença à gestante, sem prejuízo do emprego e do salário, com a duração de cento e vinte dias;

Art. XIX - licença-paternidade, nos termos fixados em lei;

Art. XXIV - aposentadoria.”

$\mathrm{O}$ inciso XXIV, do art. $7^{\circ}$ da $\mathrm{CF}$ traz o direito à aposentadoria, esta é uma das mais importantes conquistas dos trabalhadores. A situação do idoso se assemelha à da criança, pois desta não pode ser exigido esforço físico, necessitando de tempo livre para sua formação física e psicológica. O idoso deve desfrutar os últimos anos de vida sem 
coação nem obrigação de trabalhar, restando-lhe preencher seu tempo de forma voluntária: conversar com amigos, ir viajar, ler.

Considerando que o lazer é um período da vida em que não se tem a obrigação de trabalhar, dispondo de seu tempo com liberdade e espontaneidade de fazer o que for melhor para si, a aposentadoria é uma modalidade de lazer. O Estado moderno tem como objetivo fornecer a seus trabalhadores condições decentes de vida, e a aposentadoria é um dos meios para se alcançar este objetivo.

Segundo Martinez (1997, p. 284)

(...) é preciso compreender a ociosidade do jubilado não só como pagamento do salário socialmente diferido, mas situação alcançada graças ao trabalho pretérito, pois o lazer não é gratuito, prêmio, júbilo ou mérito próprio da idade alcançada.

A aposentadoria é algo alcançado através de um pagamento, sendo este pagamento o próprio tempo trabalhado, portanto esta não é uma prerrogativa ou um presente, é um direito.

$\mathrm{O}$ direito às férias, o repouso semanal remunerado e as leis que limitam a jornada diária de trabalho são uma conquista universal do trabalhador. Estes direitos visam garantir e defender o lazer.

A Consolidação das Leis do Trabalho, de 1943, dispõe nos arts. 57 a 75 sobre as regras gerais da jornada de trabalho, períodos de descanso, trabalho noturno, quadro de horário e penalidades, há também regras especiais que se encontram espalhadas por toda CLT.

A jornada diária de trabalho tende a ser limitada, observando os aspectos psicofísicos, familiar, social e outros.

Uma longa jornada de trabalho pode resultar em fadiga, acúmulo de ácido lático no organismo gerando insegurança no trabalhador, pouco rendimento e outras conseqüências que prejudicam não apenas o empregado, mas também o patrão.

O aumento da produtividade está intrinsecamente relacionado ao empenho satisfatório no trabalho (melhores condições de trabalho levam o trabalhador a se empenhar muito mais em sua atividade). O limite da jornada de trabalho acarreta na redução dos acidentes de trabalho, pois este está vinculado à atenção no trabalho. É obrigação do Estado proporcionar condições, de vida e de trabalho, decentes ao trabalhador, para que dessa forma realize a felicidade e o bem. O excesso de tempo de trabalho traz consequiências familiares, pois retira o marido e a mulher do seu lar. 
Segundo Nascimento (2001), há três conceitos de jornada diária de trabalho: o primeiro conceito diz respeito à diária de trabalho como tempo efetivamente trabalhado, excluindo as paralisações da atividade do empregado. Devemos considerar que existem paralisações remuneradas que são excluídas na jornada. Trata-se de descanso, que é contado como tempo de serviço efetivo, razão esta que torna inaceitável este conceito.

O segundo conceito proposto é a teoria da jornada diária como tempo à disposição do empregador no centro de trabalho. A jornada se inicia assim que o trabalhador chega ao local onde se apresenta e é submetido à subordinação.

O terceiro conceito é o da jornada como tempo à disposição do empregador que se apresenta no ambiente de trabalho, ou fora dele, abrangendo o período em que o empregado se desloca de sua residência para o trabalho e vice-versa, sem desvio de percurso.

No Direito Brasileiro, a posição das leis e da jurisprudência, são diferentes: na lei predomina a orientação, segundo a qual a jornada de trabalho é o tempo à disposição do empregador no centro de trabalho. $\mathrm{O}$ art. $4^{\circ}$ da CLT dispõe que: "Considera-se como de serviço efetivo o período em que o empregado esteja à disposição do empregador, aguardando ou executando ordens, salvo disposição especial expressamente consignada." Esta, portando é a regra geral apontada pela lei.

A jurisprudência do Tribunal Superior do Trabalho filiou-se à terceira teoria (pelo Enunciado n. 90), contando o tempo de serviço como aquele em que o empregado é transportado em condução do empregador, estabelecido em local sem outro meio de acesso público, de sua residência para o serviço e vice-versa. Quando houver transporte público regular, as horas in itinere remuneradas são contadas apenas onde o transporte público não alcance.

O repouso semanal originou-se com os costumes religiosos e se efetivou no século XVIII, com a Revolução Industrial.

Os princípios do repouso semanal remunerado são, de acordo com Nascimento (2001):

A semanalidade, ou seja, a cada seis dias trabalhado é proporcionado um descanso de vinte e quatro horas.

A dominicalidade, este não é obrigatório. O descanso semanal deve ser, de preferência aos domingos, em alguns casos não é possível a empresa proporcionar o dia de domingo como descanso semanal, tendo em vista as necessidades de trabalho aos domingos de alguns ramos comerciais e industriais. 
A inconversibilidade, não sendo lícito converter em pagamento o direito ao descanso semanal, podendo ser feito em feriados civis e religiosos, facultando ao empregador a substituição por outro dia compensatório ou, pagando em dobro.

A remunerabilidade igual à dos dias normais de trabalho (dias úteis), inclusive pagamentos de horas extras.

Para ocorrer à remuneração do repouso semanal deve haver a frequência integral do empregado durante a semana.

Os princípios que integram o direito às férias são os seguintes:

A anualidade, em que todo o empregado deve ter direito a férias anuais, pós decorridos 12 meses, previsto em prazo posterior para seu gozo.

A remunerabilidade, assegurando o direito à remuneração integral, como se estivesse em serviço.

A continuidade, o fracionamento da duração das férias sofre limitações, para preservar a concentração contínua do maior número de dias de descanso.

A irrenunciabilidade, o empregado não pode trocar as férias por salário, terá o direito de usufruí-las, prevendo a lei apenas parte dessa conversão em dinheiro, através do abono de férias.

A proporcionalidade, a duração das férias pode sofrer reduções em razão de ausências do empregado, como lhe pode ser assegurado um pagamento proporcional dos períodos aquisitivos não completados em decorrência da extinção do contrato de trabalho.

Assim que o empregado é admitido pela empresa ele precisa cumprir certo período para conquistar o direito de férias. Esse período é chamado de período aquisitivo, possuindo a duração de 12 meses, conforme o art. 130 da CLT: “Após cada período de 12 (doze) meses de vigência do contrato de trabalho, o empregado terá direito a férias".

Quando o empregado ficar afastado do serviço durante o período aquisitivo, nas situações de auxílio-doença concedido pelo INSS, previdenciário ou acidentário, o empregado perde o direito às férias se este afastamento ultrapassar 6 (seis) meses. Se o período de afastamento for de até seis (seis) meses, o empregado terá o direito às férias integral, sem qualquer redução. No caso de licença, ultrapassando os 30 dias, não serão concedidas às férias, assim como ocorre quando há paralisação da empresa.

Perdendo o direito às férias, quando o empregado retornar ao serviço inicia-se nova contagem de período aquisitivo. 
Se o empregador for assíduo, ou suas faltas forem justificadas, poderá gozar de seu direito integralmente. As férias serão proporcionadas em dias corridos.

Período concessivo é o período subsequente aos 12 meses (do período aquisitivo), é o período em que o empregador deve conceder as férias. Se não o fizer o empregador além de ter de pagar em dobro, deve também conceder as férias (CLT, art. 137).

Em regra, as férias devem ser concedidas de uma só vez, mas há alguns casos excepcionais, não enumerados em lei, que é possível o fracionamento em dois períodos, um desses períodos não deve ser inferior a dez dias. Conforme o art 134, da CLT:

As férias serão concedidas por ato do empregador, em um só período, nos 12 (doze) meses subsequentes à data em que o empregado tiver adquirido o direito. $\S 1^{\circ}$ - Somente em Casos excepcionais serão as férias concedidas em 2 (dois) períodos, um dos quais não poderá ser inferior a 10 (dez) dias corridos. $\S 2^{\circ}$ - Aos menores de 18 (dezoito) anos e aos maiores de 50 (cinquenta) anos de idade, as férias serão sempre concedidas de uma só vez.

Há também o direito dos estudantes, menores de 18 anos, de férias coincidentes com as férias escolares e, quando houver membros da mesma família no mesmo emprego, se não acarretar prejuízo ao empregador, deverão gozar das férias na mesma época (CLT, art. 136).

Cabe ao empregador escolher o mês em que o empregado irá gozar das férias, esta concessão será no período concessivo.

Não é permitida, em lei, a conversão integral das férias em pagamento em dinheiro. A natureza das férias é a de uma obrigação de fazer irrenunciável. É permitida a conversão de $1 / 3$ das férias (dez dias).

Estas são, de conformidade com a lei, as garantias dos empregados de possuírem o tempo livre para que, desta forma possam: descansar, refletir, questionar, divertir-se em fim, aproveitarem o seu direito ao lazer.

\section{4 - Considerações Finais}

A Revolução Industrial, ocorrida no século XVIII, modificou todo o contexto no Mundo do Trabalho: a invenção de máquinas que substituía a mão de obra de muitos homens, mudanças nos métodos de trabalho (como taylorismo e fordismo) e nas relações entre patrão e empregado. Estas transformações exigiram o aperfeiçoamento e readequação das leis trabalhistas, incluindo o direito ao lazer. 
Com as técnicas modernas surgiu a possibilidade de que o direito ao lazer, dentro de certos limites, fosse um direito de todos, distribuído por toda a coletividade. Com evolução tecnológica, o trabalhador começa a reivindicar menor número de horas na jornada de trabalho.

$\mathrm{Na}$ medida em que se iniciou a contagem do tempo de trabalho e a sua regulamentação, iniciou-se também a legalização de um período de férias, que é um espaço temporal concedido pela sociedade para a realização de atividades discricionais.

Com o surgimento da urbanização e da industrialização, os meios de comunicação de massa se desenvolvem, surge à moderna e se fortalece o lazer de massa. Os meios de comunicação de massa, a industrialização e a urbanização padronizaram as condutas sociais no lazer como elemento cultural de uma e sociedade pertencente à indústria cultural.

Apesar do tempo livre se apresentar como uma conquista jurídica, sistematizada em nossa legislação e comum a todos os indivíduos, e do lazer ser um direito reconhecido como um fundamental/social se verifica que as conquistas históricas deste direito, não são compartilhadas e usufruídas por todos.

O direito ao lazer precisa ser amplamente reconhecido pelo direito positivo. Durante a infância, por inaptidão para o trabalho, o tempo deve ser naturalmente, reservado para brincadeiras, diversões e educação. Tem a função de restaurar as energias nos períodos de trabalho e, por fim, àquele que contribuiu para criar riquezas tem o direito de se aposentar.

Expostas as características e importância do lazer apresenta-se a necessidade da sistematização deste Direito que, atualmente, encontra-se na legislação brasileira de forma dispersa e juntamente com outras garantias, e não de forma isolada.

\section{5 - Referências Bibliográficas}

ARISTÓTELES. Política. Tradução Torrieri Guimarães. São Paulo: Martin Claret, 2001.

BRASIL. Constituição (1988). Constituição da República Federativa do Brasil. São Paulo: Saraiva, 2003.

BRASIL. CLT - Consolidação das Leis do Trabalho. São Paulo, 2003.

DUMAZEDIER, Joffre. Lazer e Cultura Popular. São Paulo: Perspectiva, 1973.

LAFARGUE, Paul. O Direito à Preguiça. 2. ed. São Paulo: Hucitec, 2000. 
LEÃO XIII, Papa. Rerum Novarum: Carta encíclica de sua santidade o Papa Leão XVIII. Sobre a condição dos operários. Roma, 1981. Disponível em: $<$ http://www.montfort.org.br/documentos/rerumnovarum.html $>$. Acesso em: 05 jun. 2003.

LUKÁCS, Georg. História e Consciência de Classe. 11. ed. São Paulo: Publicações Escorpião, 1985.

MARCELLINO, Nelson Carvalho. Lazer e educação. 3 ed. Campinas: Papirus, 1995. MARTINEZ, Wladimir Novaes. Noções de Direito Previdenciário. São Paulo: LTR, 1997. v. 1.

MARX, Karl. O Capital - O Processo de Produção do Capital. 5. ed. Rio de Janeiro: Civilização Brasileira, 1980. v. 1.

MORAES, Alexandre de. Direito Constitucional. 7 ed. São Paulo: Atlas, 2000.

NASCIMENTO, Amauri Mascaro. Iniciação ao Direito do Trabalho. 27 ed. São Paulo: LTR, 2001.

REQUIXA, Renato. O Lazer no Brasil. 1 ed. São Paulo: Brasiliense, 1977.

SILVA, José Afonso da. Curso de Direito Constitucional Positivo. 19 ed. São Paulo: Malheiros Editores, 2001.

VIANNA, Segadas. Instituições de Direito do Trabalho. 18 ed. São Paulo: LTR, 1999. v. 1. 